\title{
Effects of Tree Crown Structure on Dynamic Properties of Acer rubrum L. 'Florida Flame'
}

\author{
Jason W. Miesbauer, Edward F. Gilman, and Mihai Giurcanu
}

\begin{abstract}
Knowledge of tree dynamic properties is important to improve one's ability to assess tree risk. Pull-and-release tests were performed on 16 Acer rubrum L. 'Florida Flame' trees in summer and winter over a two-year period, and natural frequency and damping ratios were calculated. One year prior to testing, trees were designated as either excurrent or decurrent and pruned to impose that form. During summer tests, trees were pruned to maintain designated form, and tests were performed before and after pruning. Trees were then systematically dissected to measure morphological and allometric characteristics. Excurrent trees had a higher natural frequency than decurrent trees in summer and winter, and pruning in summer increased the frequency of excurrent trees more than decurrent trees. Tree form and pruning had little effect on damping ratio. Decurrent trees had a larger percent of their branch mass in the top half of the crown than excurrent trees, which would subject them to larger wind-induced stress on their trunks and increase the risk of failure.

Key Words. Acer rubrum; Damping; Decurrent; Dynamics; Excurrent; Natural Frequency; Pruning; Red Maple; Tree Biomechanics.
\end{abstract}

Every year, thousands of trees are impacted by strong storms, causing severe property damage, electric outages (Simpson and Van Bossuyt 1996), human injuries, and fatalities (Schmidlin 2009). Factors such as tree form, size, condition, species, wind speed, pruning, and wood material properties impact tree resistance to windstorm damage (Putz et al. 1983; Francis 2000; Duryea et al. 2007). Trees growing in groups had a higher rate of survival than trees growing individually (Duryea et al. 2007), and removal of nearby trees predisposed surviving trees to failure by exposing them to wind forces to which they were not adapted (Gardiner et al. 1997).

Knowledge of tree dynamic properties (i.e., natural frequency and damping) is important to improve one's ability to assess tree risk. Natural frequency $(f)$ refers to the number of cycles a tree sways over a period of time and is expressed as a reciprocal of

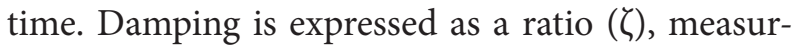
ing how well a tree is able to reduce the amplitude of its oscillation as it sways. A high damping ratio indicates that a tree is able to dissipate energy efficiently, which may reduce likelihood of uprooting or trunk failure in wind (Sellier and Fourcaud 2009). Previous studies showed linear (Mayhead
1973; Moore and Maguire 2004; Jonsson et al. 2007; Kane and James 2011), or curvilinear (Sugden 1962; Kane and James 2011) relationships between $f$ and the ratio of tree trunk diameter to height $(\mathrm{DBH} / \mathrm{Ht}$ or $\left.\mathrm{DBH} / \mathrm{Ht}^{2}\right)$. Trees in leaf had a lower $f$ and higher $\zeta$ than when they were leafless (Roodbaraky et al. 1994; Baker 1997; Kane and James 2011). Also, $f$ was higher when temperatures were below freezing (Sugden 1962; Granucci et al. 2013), likely due to stiffer wood at lower temperatures (Lieffers et al. 2001).

Several studies have examined the impact of pruning on tree response to wind loads. Gilman et al. (2008a) reported that light crown thinning of young trees was less effective at reducing trunk movement than reducing, raising, lion-tailing, or structurally pruning, and there was no difference among the latter four pruning types at wind speed of $26.8 \mathrm{~m} / \mathrm{s}$. Upper trunk movement was less for young trees with crowns that were more heavily thinned or reduced than for those that were raised, when subjected to straight line winds (Gilman et al. 2008b). Other studies found that reduction pruning was more effective in reducing bending moment than thinning or raising (Kane and Smiley 2006). Reduction pruning increased $f$ more than 
crown thinning of in-leaf Pyrus calleryana 'Bradford' trees, and more than crown raising for Quercus prinus L., but pruning did not impact $\zeta$ of in-leaf trees of either species (Kane and James 2011).

For excurrent trees, $f$ tends to be mostly influenced by the trunk, because trunk mass tends to be greater than branch mass (Sellier and Fourcaud 2009). Sellier and Fourcaud (2009) suggested that trunk sway was more similar to that of a single beam when the trunk mass dominates the crown, which might allow for more accurate predictions of tree motion. James et al. (2006) observed that species with a greater branch mass to trunk mass ratio were more damped, and the natural $f$ of the trunk dominated overall tree sway less than those with a lower ratio. Crown raising did not noticeably affect $f$ of plantation-grown Douglasfir (Pseudotsuga menziesii Mirb. Franco) trees until the lower $80 \%$ of branch mass was removed (Moore and Maguire 2005). Moore and Maguire (2005) suggested that changes in $f$ were not due to changes in damping ratio, but rather due to change in mass distribution in the trees. When dynamic wind forces act on a tree, its branches sway in a manner that is out of sync with the tree trunk. This process of energy dissipation has been referred to as mass damping (James 2003) or multiple resonance damping (Spatz et al. 2007). Branches can be thought of as a series of cantilever beams coupled to successively larger cantilever beams. The effect of branches as dampers is dependent on their mass, length, and location in the tree (Moore and Maguire 2005; James et al. 2006).

Finite element modeling (FEM) has been used to model dynamic tree behavior (Moore and Maguire 2008; Rodriguez et al. 2008; Ciftci et al. 2013) to facilitate a better understanding of tree response to wind loads. More recently, a physics-based link model has been put forth to realistically reflect tree vibrations in a simplified manner (Murphy and Rudnicki 2012). It was developed to be a more geometrically representative adaptation of a discrete model depicting a tree trunk and branches as a series of coupled mass dampers (James et al. 2006).

Although pull-and-release tests are often used to measure effects of pruning on dynamic properties of conifers (Milne 1991; Moore and Maguire 2005 ) and young deciduous trees (Kane and James 2011), the effects of pruning on dynamic properties of deciduous trees over multiple years apparently remains uninvestigated. The purpose of this study was to 1) determine the effects of imposed tree form (excurrent and decurrent), summer pruning, and season (in-leaf versus leafless) on $f$ and $\zeta$ of open-grown Acer rubrum L. trees over a two-year period; and 2) determine how mass distribution differed by tree form and how tree dynamic properties were correlated to various allometric properties based on crown form.

\section{MATERIALS AND METHODS}

\section{Pull-and-Release Tests}

Sixteen A. rubrum 'Florida Flame' trees at the University of Florida Environmental Horticulture Teaching Lab in Gainesville, Florida (USDA hardiness zone $8 b$ ) were chosen for study. Trees propagated from cuttings, with an approximate trunk diameter of $7 \mathrm{~cm}$ (measured $15 \mathrm{~cm}$ from the ground) and a height of $5 \mathrm{~m}$ were planted in April 2008 from $100 \mathrm{~L}$ plastic containers at spacing of $4 \mathrm{~m}$ and irrigated and fertilized regularly to promote growth. In July 2009 (Summer 0), tree heights averaged $6.2 \mathrm{~m}$ (st. dev. $=0.39$ ) and trunk diameters averaged 11.4 $\mathrm{cm}$ (st. dev. $=0.39$ ). Trees were designated as having either an excurrent or decurrent crown form ( $\mathrm{n}=$ 8 each) based on current crown form, and pruned to further promote the designated crown form. Excurrent trees were pruned to encourage a single, dominant main trunk by removing upright oriented secondary branches and by reducing the length of upright-oriented primary branches (i.e., those $>45$ degrees from horizontal) using reduction cuts back to smaller, more horizontally oriented lateral branches (Gilman and Lilly 2008). Decurrent trees were pruned by removing horizontally oriented lateral branches (i.e., those $<45$ degrees from horizontal), or by using reduction cuts on horizontally oriented primary branches back to smaller, more vertically oriented secondary branches to encourage vertical branch growth with many stems and branches competing for dominance in the crown (Figure 1). No primary branches were removed from the trunks. Basal diameter of all removed branches (range $0.5-2.8 \mathrm{~cm}$ ) was measured with a micro-caliper. Oven-dried mass was measured after placing branches in drying ovens for 72 hours at $105^{\circ} \mathrm{C}$. Tree height and $\mathrm{DBH}$ measurements 


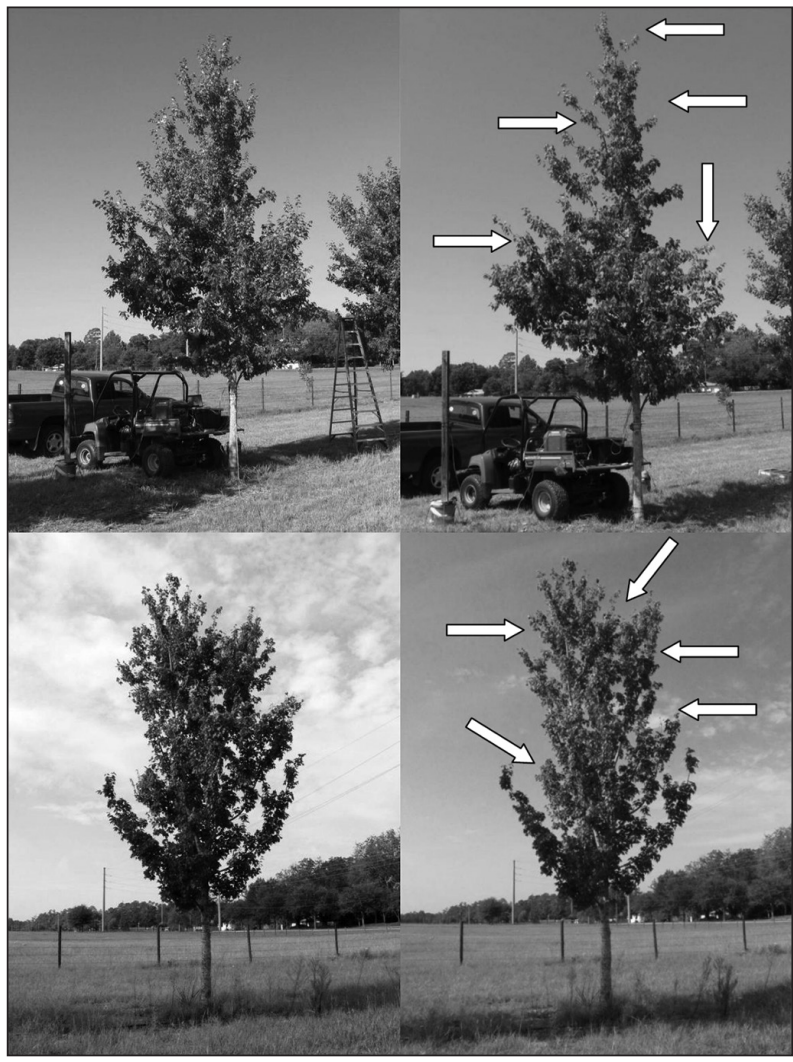

Figure 1. Excurrent (top) and decurrent (bottom) trees before pruning (left) and after pruning (right). Arrows indicate where some pruning cuts were made.

were used to determine tree slenderness ratio [tree height $(\mathrm{cm}) /$ diameter $(\mathrm{cm})$ ] at initial pruning as well as during each pull-and-release test.

To determine effect of crown form and pruning on natural frequency $(f)$ and damping ratio $(\zeta)$, pulland-release tests were conducted semi-annually over a two-year period to coincide with the in-leaf (summer) and leafless (winter) condition. Summer tests were performed June-August, 2010 (Summer 1) and June-July 2011 (Summer 2), respectively. Winter tests were conducted January-February, 2011 (Winter 1) and January 2012 (Winter 2), respectively.

Strain gauges (TML Tokyo Sokki Kenkyujo Co., Tokyo, Japan) were attached to the trunk on the azimuth 225 degrees (southwest) and azimuth 135 degrees (southeast), so that one was positioned in-line (windward side) with pull direction and the other oriented 90 degrees to pull direction. They were secured to the tree trunk using two threaded hanger bolts, $5 \mathrm{~cm}$ long and vertically spaced $10 \mathrm{~cm}$ apart. Predrilled pilot holes were used to avoid splitting the trunk. The midpoint between hanger bolts was approximately $1 \mathrm{~m}$ from the ground. The hanger bolts remained in the trunks throughout the study to ensure subsequent strain measurements would be made at the exact location, and to minimize the encroachment of wood decay organisms into the $4 \mathrm{~mm}$ diameter holes. Post hoc observations found slight discoloration but no decay in the wood around the hanger bolts.

A custom quick-release mechanism was attached to the trunk at $1 / 4$ crown height, where crown height was the distance from base of the lowest branch to tree top. The release mechanism was attached to a $14 \mathrm{~mm}$ diameter, low-stretch rope. A tractor (Kubota Tractor Corporation, Osaka, Japan) was positioned at azimuth 45 degrees (northeast) of the tree, opposite the southwest strain gauge. The rope passed through a pulley secured to the tractor bucket with a carabiner and attached to a cement block mass (100 kg) with a carabiner.

The tractor bucket was raised until the 100 $\mathrm{kg}$ mass was lifted approximately $30 \mathrm{~cm}$ off the ground, causing the tree to deflect and the rope to be near parallel with the ground. After all motion ceased, the release mechanism was triggered allowing the tree to sway freely until it came to rest. Strain gauges measured the amount of strain on the trunk as the tree swayed freely until it came to rest. The quick-release mechanism was then rotated 90 degrees and the tractor was repositioned perpendicular to the first pull direction-to a compass reading of azimuth 315 degrees (northwest) - and the pull-and-release test was repeated.

Immediately following the summer test in the northwest direction, trees were pruned as previously described to encourage their designated crown form. The main leader was not pruned, ensuring that pre-pruning and post-pruning tree heights were not different. The removed branches were dried and weighed as described above. Immediately after a tree was pruned, the pull-and-release test was repeated in both directions. Thus, there was a total of four tests per tree during summer (two tests per direction, before and after pruning $=4$ ) and two tests per tree in winter (one test per direction). One cycle of motion consisted of the full back-and-forth sway until the tree returned to the starting position, starting at the first maximum displacement in the pull direction after release in which the tree was swaying freely (represented by successive peaks in Figure 2). Three cycles were measured for each test. 


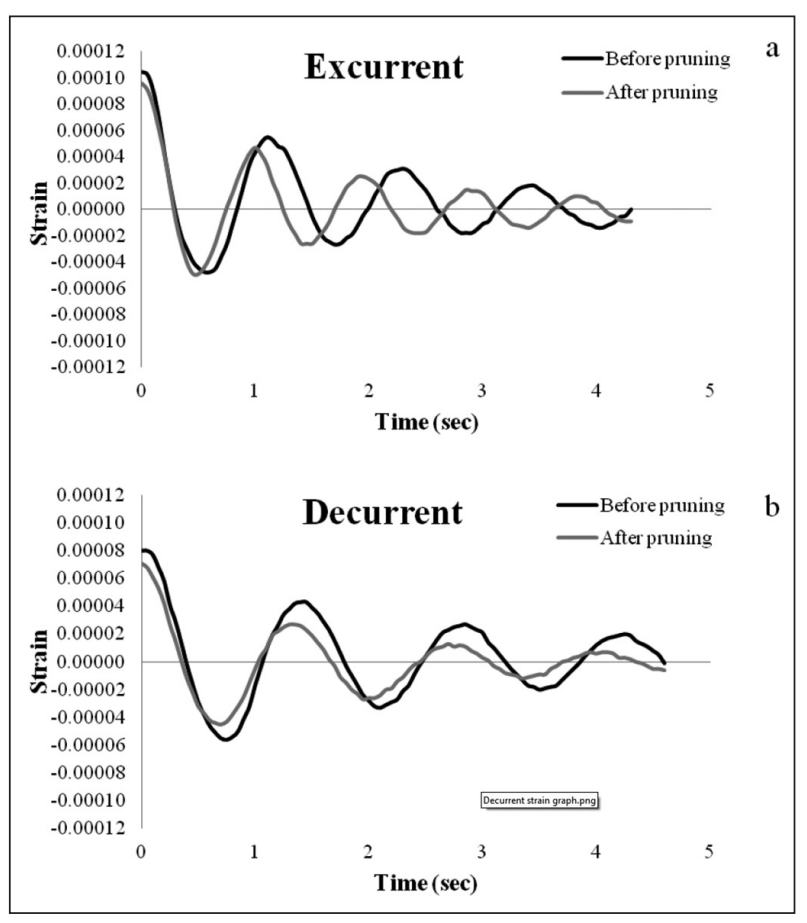

Figure 2. Strain curves for a) excurrent and b) decurrent trees before and after pruning. Each curve is from a single pull-and-release test and is typical of its respective tree forms. The distance between successive peaks represents one cycle of motion. The shorter distance between peaks shows the increase in natural frequency after pruning. The decrease in successive peak height shows the dissipation in tree sway caused by damping.

Natural frequency was calculated using the formula:

$$
f=1 / T
$$

where $T$ is the time it takes for the tree to complete one cycle of motion. Damping ratio was calculated following Kane and James (2011) (from Meriam and Kraige 2002), using the formula:

$$
\zeta=\delta /\left(4 \pi^{2}+\delta^{2}\right)^{1 / 2}
$$

where

$$
\delta=\ln \left(\mathrm{y}_{i+1} / \mathrm{y}_{i}\right)
$$

with $\mathrm{y}_{i}$ and $\mathrm{y}_{i+1}$ being subsequent maximum peaks in the plot of strain versus time (Figure 2).

All tests were conducted under calm ambient wind conditions, where wind speed was less than 2 $\mathrm{m} / \mathrm{s}$ as measured with an anemometer (Kestrel 4500,
Nielsen-Kellerman, Boothwyn, Pennsylvania, U.S.). The quick-release mechanism mass (160 g) was assumed to have a negligible effect on tree movement. Tree height and trunk diameter were measured prior to each test over the two-year period. Strain data for all tests were collected at $20 \mathrm{~Hz}$ using LabView software (National Instruments, Austin, Texas, U.S.), and recorded to a laptop computer.

\section{Destructive Analysis}

Immediately following the Winter 2 pull-and-release tests, destructive sampling and analysis occurred on 12 of the 16 trees ( $n=6$ of each form). Trees were systematically dismembered to ascertain allometric and morphologic characteristics. Trunk diameter was measured with a diameter tape immediately below and above each primary branch, as was the distance from the tape to the ground. Diameter of each primary branch was measured with a micro-caliper top-to-bottom and side-to-side. Branch base angle was measured by placing a $16.5 \mathrm{~cm}$ long digital level (SmartTool $^{\mathrm{Tx}}$, M-D Building Products, Oklahoma City, Oklahoma, U.S.) on the branch adjacent to the union. Total branch angle from base to tip was measured by placing the digital level at the branch base and sighting a line to the tip of the primary branch, where the primary branch was considered to be the larger of the branches at each bifurcation.

Tree crown was separated into 16 sections based on azimuth direction and vertical quartile. Tree crown was separated into four quadrants based on azimuth direction: $\mathrm{NE}=0-89$ degrees, $\mathrm{SE}=90-179$ degrees, $\mathrm{SW}=180-269$ degrees, $\mathrm{NW}=270-360$ degrees. Branches were categorized as being in one of the quadrants based on azimuth of branch base origination from trunk. Crown height (vertical distance from the base of the lowest branch to the tree top) was divided into four vertical quartiles of equal proportion: $0 \%-24 \%, 25 \%-49 \%$, $50 \%-74 \%$, and $75 \%-100 \%$ crown height. Trees were systematically dismembered starting at the top. All primary branches originating on the trunk in the top quartile $(75 \%-100 \%)$ were removed at the trunk; the top quartile of the trunk was also removed. Several branches originated lower on the trunk but had portions that grew up into the $75 \%-100 \%$ quartile of the crown; any portion of that branch that grew up into the top quartile was cut with a heading cut and marked with the unique 
number of the primary branch on which it originated. Thus, the tree was "flat topped" by removing $25 \%$ of the crown height. Length was measured of each primary branch segment from branches originating in the top quartile, as well as from any branches originating lower in the crown, and trunk length in the top quartile. Total fresh mass was recorded separately for each branch (primary branch and all lateral branches) and the trunk. The remaining three quartiles were subsequently removed from the tree in descending order from the tree top, and length and mass for branches and trunk sections were measured in the same manner. The remaining trunk below the crown was cut at ground level, and length and mass were measured.

Total branch length was the sum of primary branch segment lengths in each quartile and total branch mass was the cumulative mass from each quartile. Branch length and mass were categorized as being in the directional quadrant in which the branch originated on the trunk. Total trunk length and mass were the cumulative trunk segments from the four vertical quartiles plus the trunk below crown. All length and mass measurements were made within one hour of being removed from the tree. Measuring trees in this manner allowed researchers to divide the tree canopy into 16 segments based on quartile and quadrant (four directional quadrants $\times$ four vertical quartiles).

\section{Data Analysis}

The experimental design was a split plot with tree form as the whole plot factor; pruning, cycle, and year were the split plot factors. Each tree was pulled from the northeast and northwest direction, giving two observations per combination of treatments. Preliminary analysis showed that direction had no impact on response variables, and since direction was arbitrarily chosen it was not included in the statistical model.

For tests performed in summer, a four-way factorial analysis of variance (ANOVA) was used to determine the effects of form, pruning, cycle, year, and all interactions on $f$ and $\zeta$ values. In winter, a three-way factorial ANOVA tested the effects of form, cycle, year and all interactions on $f$ and $\zeta$ values. For all ANOVAs, season, form, year, cycle and all their interactions were main effects, tree was a random effect in the models.
A four-way factorial ANOVA tested for differences in $f$ and $\zeta$ between pulls performed on post-pruned trees in summer (in-leaf) and in winter when trees were leafless. Season, form, year, cycle, and all their interactions were main effects in the model and tree was a random effect.

A two-way ANOVA tested differences in branch mass removed between excurrent and decurrent trees from each of the three annual (Summer 0,1,2) pruning events. One-way repeated measures ANOVA, with year as the within subject factor, was used to test differences in height and diameter between excurrent and decurrent trees over the two-year period.

Regression analysis was used to examine the relationship between $\mathrm{DBH} / \mathrm{Ht}^{2}$ and $f$, and if that relationship was influenced by form, pruning, and year. Regression analysis examined whether $f$ and $\zeta$, measured on the subset of twelve dissected trees, could be predicted with the independent variables associated with the following: trunk and branch length and mass attributes; trunk taper; distribution of branch length and mass by vertical quartile and directional quadrant; branch base angle and total branch angle. T-tests were performed to analyze allometric and morphological differences by tree form. Only Winter 2 values for $f$ and $\zeta$ were analyzed because dissections occurred immediately after Winter 2 tests.

Statistical analyses were performed in SAS version 9.2 (SAS Institute, Cary, North Carolina, U.S.) using the PROC MIXED, GLIMMIX, GLM, REG, TTEST, and UNIVARIATE procedures. Mean separations were analyzed for main effects and interactions using Tukey's HSD test. Differences were considered significant at a level of $\alpha=0.05$.

\section{RESULTS AND DISCUSSION}

The same branch mass was removed in the initial (Summer 0) excurrent and decurrent pruning treatments (Table 1). The retained lateral branches adjacent to the reduction cuts on excurrent trees reoriented upward (not measured) in the subsequent 12 months (Summer 1), likely due to loss of apical control caused by removal of the primary terminal (Wilson 2000).Consequently, many branches on excurrent trees required more aggressive pruning than the decurrent trees at the second and third pruning episodes (Summers 1 and 2) to maintain the targeted excurrent crown 
form. Reducing stems and branches that compete with the leader as was done for excurrent trees has been shown to slow diameter growth of the pruned branches and increase diameter growth of the unpruned trunk and thereby reducing branch aspect ratio (Gilman and Grabosky 2009). Because branches that have a small aspect ratio are more strongly attached to the tree (Gilman 2003; Kane 2007), arborists have embraced this pruning strategy on young shade trees (Gilman and Lily 2008). Despite having more mass removed from excurrent trees in the second and third pruning events, tree height and trunk diameter were not different from decurrent trees (Table 1). Others have found little difference in trunk diameter growth rate following removal of different amounts of foliage (Hanley et al. 1995; Pinkard and Beadle 1998a; Pinkard and Beadle 1998b). Therefore, differences between treatments can be attributed to changes in crown form, not tree size.

\section{Natural Frequency}

The three-way interaction form $\times$ prune $\times$ year was significant, so no main effects or two-way interactions will be discussed. Excurrent trees had a higher $f$ than decurrent trees both before and after pruning in both summers (Figure 3 ). In Summer 1, pruning increased $f$ of excurrent trees, but had no effect on decurrent trees; whereas in Summer 2, pruning increased $f$ of both forms, but the difference was much greater for excurrent trees (Figure 3). Quantity of branch mass removed may have influenced pruning-induced $f$ increase. Summer 1 and 2 branch mass removed from excurrent trees was 1.7 and 2.5 times greater than from decurrent trees, respectively (Table 1 ). However, excurrent trees had a greater Summer 1 pre-prune $f$ than decurrent in response to removing the same amount of branch mass one year earlier (in Summer 0). Kane and James (2011) also reported that $f$ was influenced by location of the removed branches. Crown reduction in that study increased $f$ more than crown raising (pruning treatment that removes lower branches), even though less mass was removed from reduced trees. Crown reduction and raising both reduced crown height (i.e., the distance from the lowest limb of the crown to the top of the tree) but branch removal from the upper part of the crown (i.e., reduction) increased $f$ more effectively, as was found in the present study (described hereafter).

Summer $f$ values in the present study were similar to values measured on deciduous trees of similar size from pull-and-release tests (Roodbaraky et al. 1994; Kane and James 2011) or from observations on landscape trees in ambient wind (Baker 1997). As in summer, excurrent trees had a higher $f$ than decurrent trees in both winters (Figure 4). Frequency was greater in Winter 2 than Winter 1 for excurrent trees, but was lower in Winter 2 than Winter 1 for decurrent trees. This disparity may be a residual effect of differences in removed branch mass and location during Summer 2 pruning treatments, as natural frequency tends to be higher for trees with a lower center of mass (Sugden 1962; Sellier and Fourcaud 2005). Although crown position of removed branch mass was not recorded, visual inspection of digital images of pre-pruned and post-pruned trees indicated that more branch mass was removed from the upper portion of the crown on excurrent trees and from the lower and middle portions of the crown of decurrent trees. Furthermore, destructive analysis after Winter 2 tests indicated that excurrent trees had greater branch mass in the lower portion of the crown than decurrent trees (described hereafter).

Table 1. Mean (SD) tree height, trunk diameter, $\mathrm{DBH} /$ height(Ht)2 $^{2}$, crown height, and removed branch dry mass over three summers.

\begin{tabular}{|c|c|c|c|c|c|c|}
\hline Summer & Tree form & $\begin{array}{l}\text { Tree height } \\
(\mathrm{m})\end{array}$ & $\begin{array}{l}\text { Trunk diameter } \\
(\mathrm{DBH})(\mathrm{cm})\end{array}$ & $\mathrm{DBH} / \mathrm{Ht}^{2}$ & $\begin{array}{l}\text { Crown height } \\
(\mathrm{m})\end{array}$ & $\begin{array}{l}\text { Removed branch } \\
\text { dry mass }(\mathrm{g})\end{array}$ \\
\hline \multirow[t]{2}{*}{0} & Excurrent & $6.1(.23) \mathrm{a}$ & $8.4(.31) \mathrm{a}$ & $0.22(.02) \mathrm{a}$ & $4.5(.27) \mathrm{a}$ & $2262.4(596.0) \mathrm{a}$ \\
\hline & Decurrent & $6.3(.16) \mathrm{a}$ & $8.2(.24) \mathrm{a}$ & $0.21(.01) \mathrm{a}$ & $4.6(.15) \mathrm{a}$ & $2050.1(496.7) a$ \\
\hline \multirow[t]{2}{*}{1} & Excurrent & $7.1(.28) \mathrm{a}$ & $9.8(.35) \mathrm{a}$ & $0.20(.02) \mathrm{a}$ & $5.5(.30) \mathrm{a}$ & $3043.9(1112.1) \mathrm{a}$ \\
\hline & Decurrent & $7.0(.30) \mathrm{a}$ & $9.7(.27) \mathrm{a}$ & $0.20(.02) \mathrm{a}$ & $5.3(.29) \mathrm{a}$ & $1780.1(503.2) \mathrm{b}$ \\
\hline \multirow[t]{2}{*}{2} & Excurrent & $7.8(.27) \mathrm{a}$ & $11.4(.44) \mathrm{a}$ & $0.19(.01) \mathrm{a}$ & $6.2(.27) \mathrm{a}$ & $6993.0(2963.5) \mathrm{a}$ \\
\hline & Decurrent & $7.8(.34) \mathrm{a}$ & $11.5(.29) \mathrm{a}$ & $0.19(.02) \mathrm{a}$ & $6.1(.29) \mathrm{a}$ & $2744.2(910.5) b$ \\
\hline
\end{tabular}

Note: Means in a column within a summer followed by the same letter between tree forms are not significantly different at $P<0.05$. 


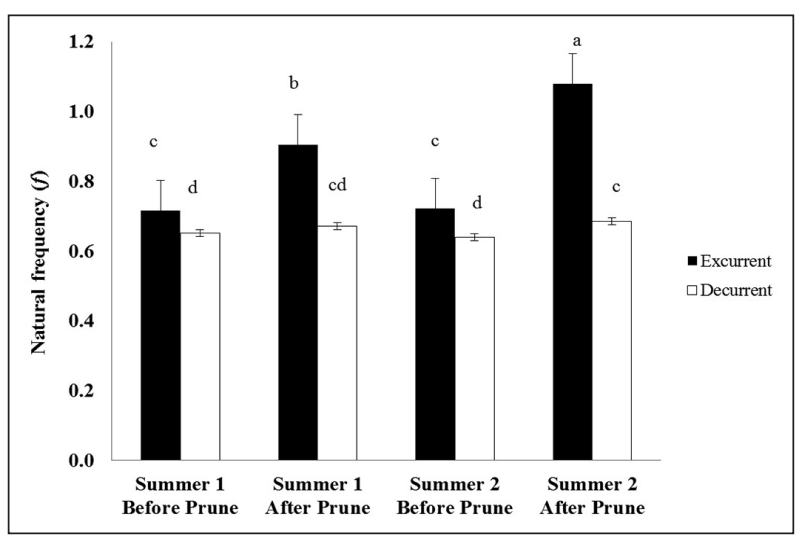

Figure 3. Natural frequency $(f)$ of Acer rubrum trees with excurrent and decurrent form in summer before and after pruning over a two-year period. Bars with the same letter are not significantly different at $P<0.05$.

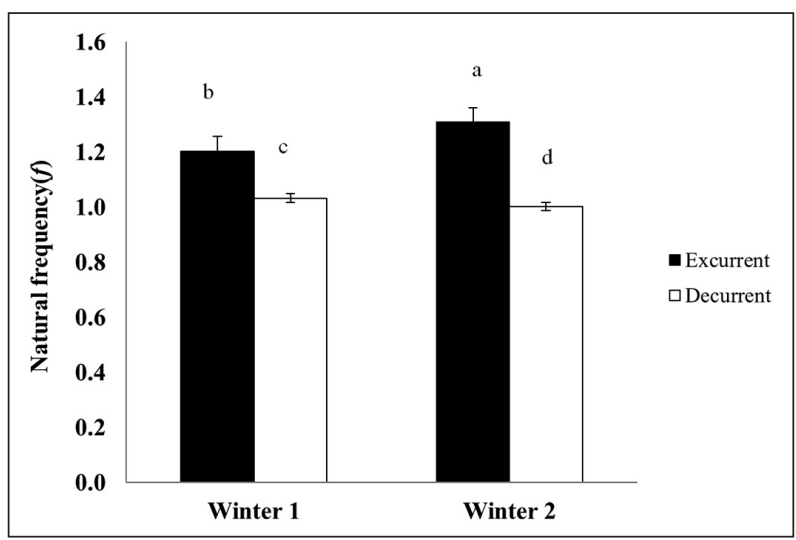

Figure 4. Natural frequency $(f)$ of Acer rubrum trees with excurrent and decurrent form during winter tests over a twoyear period. Bars with the same letter are not significantly different at $P<0.05$.

Although $f$ of excurrent trees increased immediately after trees were pruned in Summer 1, $f$ one year later (Summer 2 pre-prune) had returned to the Summer 1 pre-prune $f$ (Figure 3). Decurrent trees, whose Summer 1 post-pruning $f$ did not increase compared to pre-pruning, also had the same $f$ one year later (Summer 2 pre-prune). This suggests that trees responded to pruning by adapting their growth to maintain a functional biomechanical equilibrium in their response to external forces. Zeng (2003) showed that heavily pruned trees $(50 \%-70 \%$ crown removal) partitioned new growth biomass proportionally more toward leaves than wood compared to unpruned or lightly pruned ( $20 \%$ crown removal) trees. Heavily pruned trees returned to the same leaf to wood mass ratio as unpruned and lightly pruned trees one year later; pruning treatments were repeated on the same trees a second year with similar results. The author suggested that there may be a functional equilibrium between photosynthetic tissue (foliage) and wood biomass within branches, similar to that between roots and shoots (Poorter and Nagel 2000). Adaptive growth to the physical environment is common in trees. For example, wind-exposed Picea sitchensis (Bong. Carrière) growing on the forest stand edge were more tapered, had a higher $f$, and were more damped than trees growing mid-stand (Bruchert and Gardiner 2006). However, clonally propagated trees of the same age, height, and diameter, with two different mechanically imposed (pruned) crown forms, returning to the same pre-pruning frequency from the previous year, have never been reported. Future research into long-term responses of trees to repeated pruning treatments is needed to better understand how to optimally maintain urban trees so they can cope with their environments.

When summer post-prune (in-leaf) and winter (leafless) tests were compared, $f$ for both forms was greater in winter than summer, and excurrent trees had a greater $f$ than decurrent trees (Figure 5), which is consistent with previous studies (Roodbaraky et al. 1994; Kane and James 2011). When $f$ for both seasons was pooled to analyze differences in form by year, $f$ was greater in Year 2 than Year 1 for excurrent trees, but not for decurrent trees. When data for both forms were pooled, $f$ in winter was greater than in summer, and $f$ was greater in Year 2 than Year 1 for both seasons (Figure 5). The three-way interaction form $\times$ season $\times$ year was not significant $(P=0.46)$. The presence of foliage likely explains most of the difference in $f$ between seasons (Sellier and Fourcaud 2005). Although low temperature can increase $f$ in winter (Granucci et al. 2013) and branches are stiffer (Lieffers et al. 2001) when trees were frozen, all tests in the present study were conducted above $5^{\circ} \mathrm{C}$, so it is likely that the leafless condition was the primary cause of increased $f$ during winter.

Frequency decreased as the percent of total branch mass (PBM) within the top half of the crown increased (Figure 6). This appears to be in agreement with previous studies that found $f$ decreased as the height of the center of mass 
increased (Sugden 1962; Sellier and Fourcaud 2005). Lower tree sway frequency could increase the likelihood that frequency of the tree and wind will synchronize, creating a situation that maximizes the amount of tree movement (Sellier and Fourcaud 2009). More mass toward the top of the crown would also place more bending stress on the trunk and into roots during strong winds (Kane and Smiley 2006; Gilman et al. 2008a), increasing the likelihood of stem or root failure. Inspection of pre-pruning and post-pruning digital images revealed that pruning excurrent trees appeared to remove more crown area from the upper portions of the crown than decurrent trees; more importantly, destructive analysis showed that decurrent trees had a much greater PBM located in the upper half of their crown (mean = $39.8 \%$ ) than excurrent trees (mean $=14.4 \%$; $\mathrm{SE}$ $=3.48 ; P<0.0001$ ). Trees with a decurrent form may have an increased likelihood of damage in windstorms because a larger crown area farther from the ground, where wind speeds are higher (de Langre 2008), will create larger drag forces and bending moments on the trunk (Kane et al. 2008; Sellier and Fourcaud 2009). Trees with the excurrent habit retain proportionally greater mass lower to the ground than decurrent trees (Figure 6) which may be responsible for excurrent trees having lower amounts of damage among trees that survived in hurricanes (Duryea et al. 2007).

Contrary to previous reports of a linear (Moore and Maguire 2004; Jonsson et al. 2007) or curvilinear (Kane and James 2011) relationship between $\mathrm{DBH} / \mathrm{Ht}^{2}$ and $f$, the present study found no relationship between $\mathrm{DBH} / \mathrm{Ht}^{2}$ and $f$ during summer for excurrent $(P=0.93)$ or decurrent trees $(P=0.09)$. For winter tests, there was a weak but significant relationship between $\mathrm{DBH} / \mathrm{Ht}^{2}$ and $f$ when all trees were analyzed together $\left(\mathrm{R}^{2}=0.17\right)$, but when analyzed separately, by form or by year, there was no relationship between $\mathrm{DBH} / \mathrm{Ht}^{2}$ and $f$. Poor correlation was probably due to homogeneity of tree height and diameter among test trees (Table 1). Future experiments investigating the relationship between $\mathrm{DBH} / \mathrm{Ht}^{2}$ and $f$ on deciduous trees with a wide range of heights and diameters may reveal significant relationships.

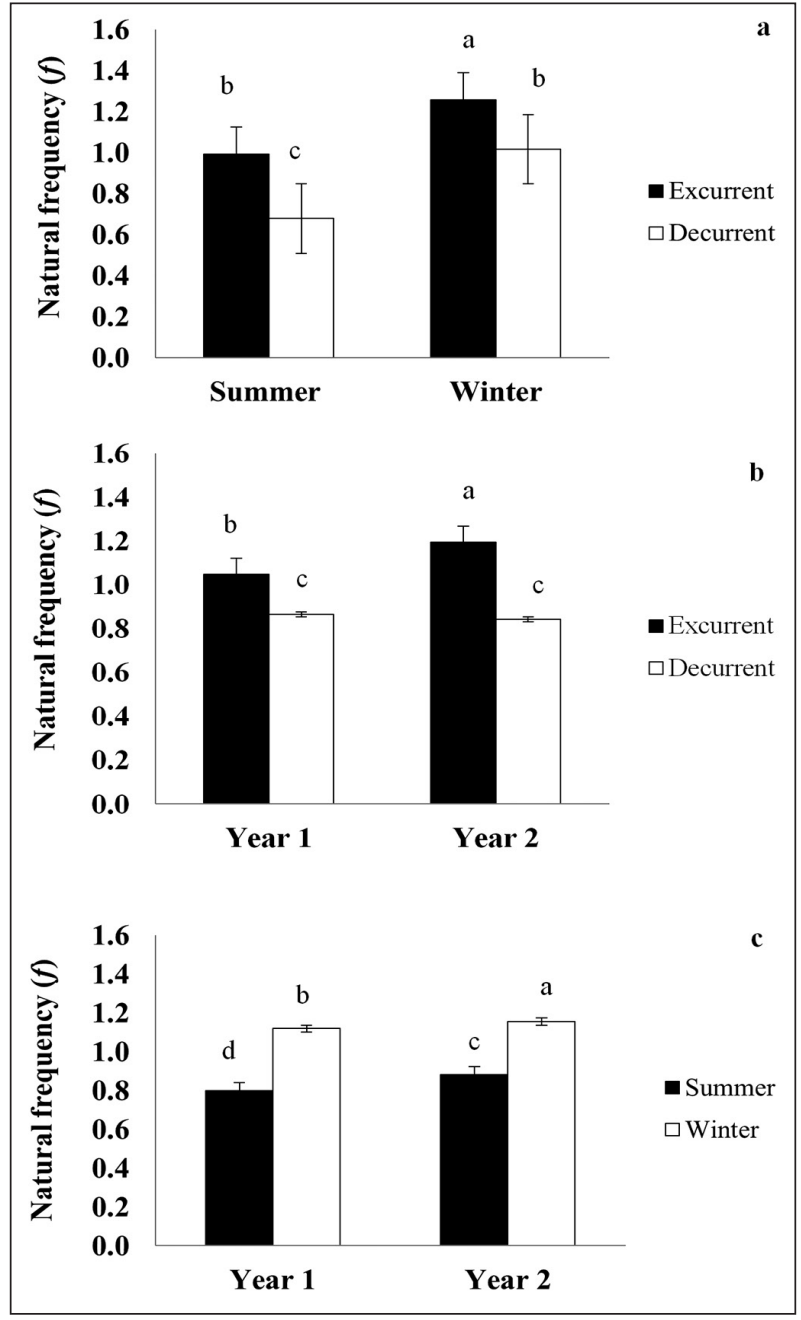

Figure 5. Natural frequency $(f)$ of Acer rubrum trees for summer post-pruning and winter tests conducted over a two-year period showing significant interactions a) form $x$ season, with tests from both years pooled within season; $b$ ) form $\times$ year, with tests from both seasons pooled together within each year; c) season $\times$ year, with trees of both forms pooled together. Bars with the same letter are not significantly different at $P<0.05$.

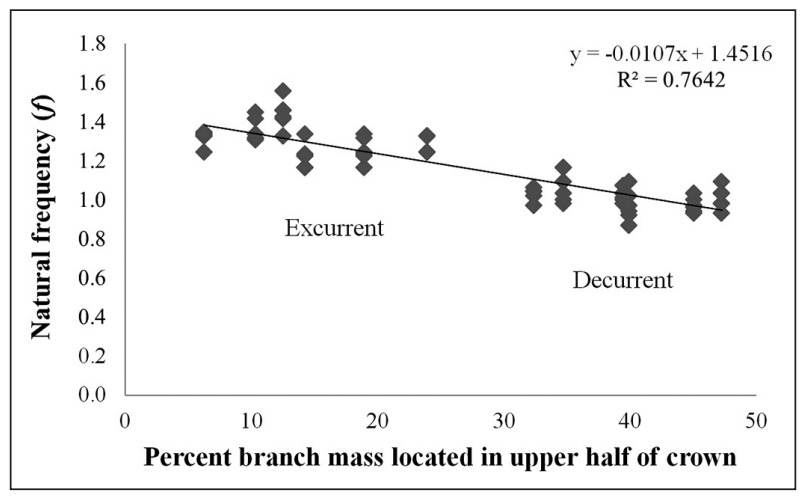

Figure 6. Relationship between the percent of branch mass located in the upper half of the crown and natural frequency $(f)$ for trees dissected after Winter 2 pull-and-release tests. 


\section{Damping Ratio}

Theeffects of treatmentson damping ratio werevaried. Summer tests indicated the three-way interaction form $\times$ prune $\times$ cycle significantly impacted $\zeta$. Mean $\zeta$ in Cycle 3 was lower than Cycle 1 before and after pruning on excurrent trees, as well as before pruning on decurrent trees (Figure 7). However, Cycle 3 $\zeta$ was higher after pruning on decurrent trees and not different than Cycle 1. It is unclear why damping ratio for Cycle 3 of decurrent trees increased after pruning. One possible explanation is that branch mass distribution was greater in the upper part of the crown after the pruning treatment, as more branch mass was apparently removed from the lower portion of decurrent tree crowns. Mean $\zeta$ for Cycles 1 and 2 was not different between forms and was not affected by pruning. It appeared that most damping of sway motion occurred during the first two cycles of motion, and pruning did not negatively affect trees ability to dampen their sway motion. This is in agreement with Kane and James (2011), who reported that pruning did not impact $\zeta$ of inleaf $P$. calleryana 'Bradford' or Q. prinus. James et al. (2006) observed that although branch mass on trees with an excurrent form was small relative to trunk mass, they were effective at damping trunk sway. Damping ratio has not been associated with injury in wind storms, and was not influenced by crown form in the current study. Moreover, increased wind speed in straight line gusts has been associated with more bending (Gilman et al. 2008a; Kane et al. 2008) and breakage (Duryea et al. 2007), and may be more responsible than high damping ratios for damaging trees in storms. Although it has been suggested that higher damping ratios may lend more stability to trees in wind (James et al. 2006), this has not been documented in the literature. Because of the complexity of the mechanisms involved with mass damping from branches, more research is needed on branch and stem sway motions during storms that induce failure, to better describe this process. It should be noted that the experimental design of the present study required that data were collected in calm and ambient wind conditions.

When winter $\zeta$ was analyzed alone, there were significant differences by cycle and by form. Decurrent trees had a slightly greater $\zeta$ than excurrent trees (Table 2a). Cycle 1 was more damped than Cycles 2 and 3 (Table 2b). However, when $\zeta$ of

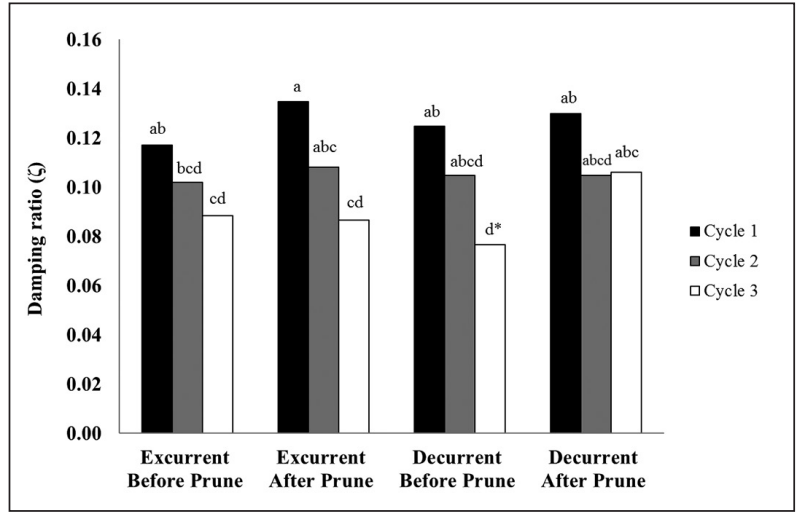

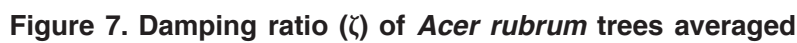
over two years with excurrent and decurrent forms in summer before and after pruning for three sway cycles. Bars with the same letter are not significantly different (*except Decurrent Before Prune Cycles 1 and 3, which are significantly different from each other) at $P<0.05$.

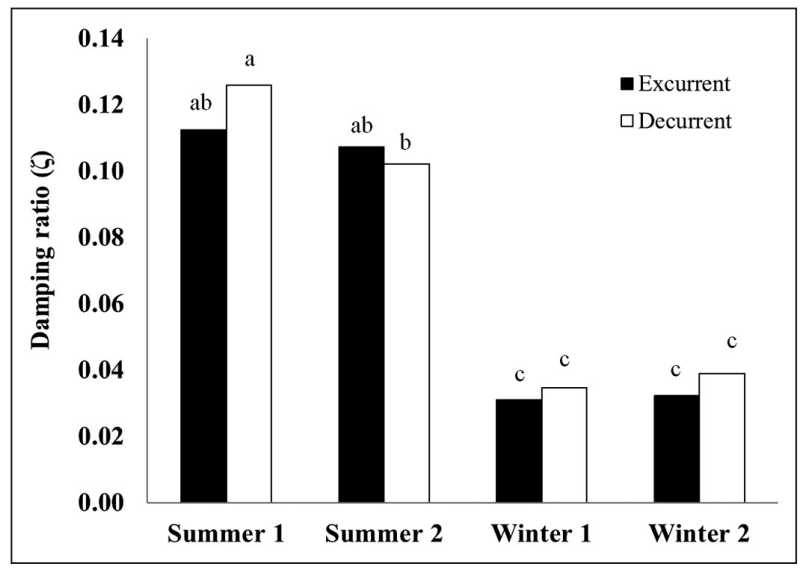

Figure 8. Three-way interaction form $\times$ season $\times$ year for summer post-pruning (in-leaf) and winter (leafless) damping

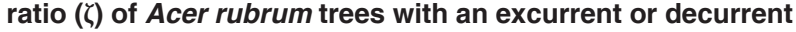
form over two years.

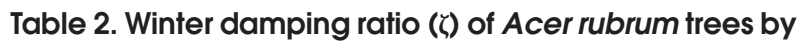
a) Form and b) Cycle.

\begin{tabular}{ll}
\hline a) Form & Mean damping ratio (SE) \\
Decurrent & $0.037(.002) \mathrm{a}$ \\
Excurrent & $0.032(.002) \mathrm{b}$ \\
& \\
b) Mean damping ratio (SE) & \\
Cycle1 & $0.042(.002) \mathrm{a}$ \\
Cycle2 & $0.030(.002) \mathrm{b}$ \\
Cycle3 & $0.031(.002) \mathrm{b}$ \\
\hline
\end{tabular}

Note: Values with the same letter are not significant at $P<0.05$.

summer post-prune (in-leaf) and winter (leafless) trees were analyzed together there were no differences between forms for winter $\zeta$ (Figure 8). The three-way interaction form $\times$ season $\times$ year was significant. Decurrent trees had a greater $\zeta$ in Summer 1 than Summer 2, but $\zeta$ did not differ between 
Summer 1 and 2 for excurrent trees. Trees in winter (leafless) were $70 \%$ less damped than summer (in-leaf), which is consistent with reductions in $\zeta$ of leafless trees for Bradford pear (75\%; Kane and James 2011) and London planetree (Platanus) (90\%; Roodbaraky et al. 1994). Sellier and Fourcaud (2005) reported that foliage was the major source of damping of Pinus pinaster saplings. The reduction in damping when trees are leafless may be of little consequence if drag forces are the primary cause of damage to trees because leaf area is strongly correlated to drag forces (Kane and Smiley 2006).

Computer modeling showed an inverse relationship between $\zeta$ and $f$ for Pinus pinaster (Sellier and Fourcaud 2009). The authors suggest that tree characteristics that would cause a tree to have a lower sway frequency would also cause a tree to be more damped, thereby offsetting the increased risk of wind-induced damage. Based on field measurements, Bruchert and Gardiner (2006) reported an inverse relationship between $\zeta$ and $f$ for forestgrown Picea sitchensis trees that followed a longitudinal gradient from stand edge to mid-stand. The natural frequency of trees near the stand edge (10 $\mathrm{m})$ was higher and the damping ratio was lower than trees farther into the stand $(90 \mathrm{~m})$. Unfortunately, there is a scarcity of reports from field measurements correlating natural frequency and damping ratios of open-grown deciduous trees. The results of the present study partially support the inverse relationship between $\zeta$ and $f$. When all trees from summer tests were pooled (both forms, before and after pruning) by year, $\zeta$ in Year 1 (mean $=0.1133)$ was greater than in Year 2 (mean $=$ 0.1007; $\mathrm{SE}=0.003 ; P<0.05)$. Mean $f$ was lower in Summer 1 than Summer 2, although the effect of Year was superseded by the three-way interaction form $\times$ prune $\times$ year (Figure 3 ). In other words, $\zeta$ increased while $f$ decreased from Year 1 to Year 2, but interactions with other factors prevent definitive conclusions to be drawn. More field measurements are needed on various species of open-grown amenity trees to explore this hypothesis further.

\section{CONCLUSIONS}

Excurrent trees had a higher natural frequency than decurrent trees in summer and winter, and the pruning in summer increased the frequency of excurrent trees more than decurrent trees. Damping ratio was not affected by pruning for either crown form, except for Cycle 3 on decurrent trees. Decurrent trees had a larger percent of their branch mass in the top half of the crown than excurrent trees, which could subject them to larger wind-induced stress on their trunks and increase the risk of failure. Researchers of the current study conclude that structurally pruning to reduce length of upright branches competing with the leader on young red maple (Acer rubrum L. 'Florida Flame') trees to maintain an excurrent form reduces the risk of wind-induced tree failure. Although pruning caused frequency to increase in Year 1, trees returned to the same pre-pruned frequency by Year 2, which may suggest a functional biomechanical equilibrium that trees maintain in their environments. Pull-and-release tests on annually pruned trees over multiple years could help elucidate this further.

Acknowledgments. We would like to thank Chris Harchick for technical assistance on this project. Thank you to the TREE Fund and GreatSouthernTreeConference.org for funding this project.

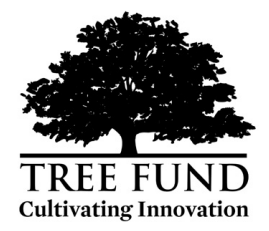

\section{LITERATURE CITED}

Baker, C.J. 1997. Measurements of the natural frequencies of trees. Journal of Experimental Botany 48:1125-1132.

Bruchert, F., and B. Gardiner. 2006. The effect of wind exposure on the tree aerial architecture and biomechanics of Sitka spruce (Picea sitchensis, Pinaceae). American Journal of Botany 93:1512-1521.

Ciftci, C., S.F. Brena, B. Kane, and S.R. Arwade. 2013. The effect of crown architecture on dynamic amplification factor of an opengrown sugar maple (Acer saccharum L.). Trees 27:1175-1189.

de Langre, E. 2008. Effects of wind on plants. Annual Review of Fluid Mechanics 40:141-168.

Duryea, M.L., E. Kampf, and R.C. Littell. 2007. Hurricanes and the urban forest: I. Effects on southeastern United States coastal plain tree species. Arboriculture \& Urban Forestry 33:83-97.

Francis, J.K. 2000. Comparison of hurricane damage to several species of urban trees in San Juan, Puerto Rico. Journal of Arboriculture 26:189-196.

Gardiner, B.A., G.R. Stacey, R.E. Belcher, and C.J. Wood. 1997. Field and wind tunnel assessments of the implications of respacing and thinning for tree stability. Forestry 70:233-252.

Gilman, E.F. 2003. Branch-to-stem diameter ratio affects strength of attachment. Journal of Arboriculture 29:291-294.

Gilman, E.F., and J.C. Grabosky. 2009. Growth partitioning three years following structural pruning of Quercus virginiana. Arboriculture \& Urban Forestry 35:281-286.

Gilman, E.F., and S. Lilly. 2008. Best management practices: Tree pruning (second edition). International Society of Arboriculture, Champaign, Illinois, U.S. 
Gilman, E.F., F.J. Masters, and J.C. Grabosky. 2008b. Pruning affects tree movement in hurricane-force winds. Arboriculture \& Urban Forestry 34:20-28.

Gilman, E.F., J.C. Grabosky, S. Jones, and C. Harchick. 2008a. Effects of pruning dose and type on trunk movement in tropical storm winds. Arboriculture \& Urban Forestry 34:13-19.

Granucci, D., M. Rudnicki, A. Hiscox, D. Miller, and H-B. Su. 2013. Quantifying the effects of freezing on tree sway frequencies. Agriculture and Forest Meteorology 168:10-14.

Hanley, D.P., C.D. Oliver, D.A. Maguire, D.G. Briggs, and R.D. Fight. 1995. Forest pruning and wood quality of western North American conifers. College of Natural Resources, University of Washington, Seattle, Contribution No. 77.

James, K. 2003. Dynamic loading of trees. Journal of Arboriculture 29:165-171.

James, K.R., N. Haritos, and P.K. Ades. 2006. Mechanical stability of trees under dynamic loads. American Journal of Botany 93:1522-1530.

Jonsson, M.J., A. Foetzki, M. Kalberer, T. Lundstrom, W. Ammann, and V. Stockli. 2007. Natural frequencies and damping ratios of Norway spruce [Picea abies (L.) Karst] growing on subalpine forested slopes. Trees 21:541-548.

Kane, B. 2007. Branch strength of Bradford pear (Pyrus calleryana var. 'Bradford'). Arboriculture \& Urban Forestry 33:283-291.

Kane, B., and E.T. Smiley. 2006. Drag coefficients and crown area estimation of red maple. Canadian Journal of Forest Research 36:1951-1958.

Kane, B., and K.R. James. 2011. Dynamic properties of open-grown deciduous trees. Canadian Journal of Forest Research 41:321-330.

Kane, B., M. Pavlis, J.R. Harris, and J.R. Seiler. 2008. Crown reconfiguration and trunk stress in deciduous trees. Canadian Journal of Forest Research 38:1275-1289.

Lieffers, S.M., V.J. Lieffers, U. Silins, and L. Bach. 2001. Effects of cold temperatures on breakage of lodgepole pine and white spruce twigs. Canadian Journal of Forest Research 31:1650-1653.

Mayhead, G.J. 1973. Sway periods in forest trees. Scottish Forestry 27:19-23.

Meriam, J.L., and L.G. Kraige. 2002. Engineering Mechanics. Vol. 2. Dynamics (fifth edition). Wiley \& Sons, Inc., Hoboken, New Jersey, U.S.

Milne, R. 1991. Dynamics of swaying of Picea sitchensis. Tree Physiology 9:383-399.

Moore, J.R., and D.A. Maguire. 2004. Natural sway frequencies and damping ratios of trees: Concepts, review, and synthesis of previous studies. Trees 18:195-203.

Moore, J.R., and D.A. Maguire. 2005. Natural sway frequencies and damping ratios of trees: Influence of crown structure. Trees 19:363-373.

Moore, J.R., and D.A. Maguire. 2008. Simulating the dynamic behavior of Douglas-fir trees under applied loads by the finite element method. Tree Physiology 28:75-83.

Murphy, K.D., and M. Rudnicki. 2012. A physics-based link model for tree vibrations. American Journal of Botany 99:1918-1929.

Pinkard, E.A., and C.L. Beadle. 1998a. Effects of green pruning on growth and stem shape of Eucalyptus nitens (Deane and Maiden) Maiden. New Forests 15:107-126.
Pinkard, E.A., and C.L. Beadle. 1998b. Aboveground biomass partitioning and crown architecture of Eucalyptus nitens following green pruning. Canadian Journal of Forest Research 28:1419-1428.

Poorter, H., and O. Nagel. 2000. The role of biomass allocation in the growth response of plants to different levels of light, $\mathrm{CO}_{2}$, nutrients, and water: A quantitative review. Australian Journal of Plant Physiology 27:595-607.

Putz, F.E., P.D. Coley, K. Lu, A. Montalvo, and A. Aiello. 1983. Uprooting and snapping of trees: Structural determinants and ecological consequences. Canadian Journal of Forest Research 13:1011-1020.

Rodriguez, M., E. De Langre, and B. Moulina. 2008. A scaling law for the effects of architecture and allometry on tree vibration modes suggests a biological tuning to modal compartmentalization. American Journal of Botany 95:1523-1537.

Roodbaraky, H.J., C.J. Baker, A.R. Dawson, and C.J. Wright. 1994. Experimental observations of the aerodynamic characteristics of urban trees. Journal of Wind Engineering and Industrial Aerodynamics 52:171-184.

Schmidlin, T.W. 2009. Human fatalities from wind-related tree failures in the United States, 1995-2007. Natural Hazards 50:13-25.

Sellier, D., and T. Fourcaud. 2005. A mechanical analysis of the relationship between free oscillations of Pinus pinaster Ait. saplings and their aerial architecture. Journal of Experimental Botany 56:1563-1573.

Sellier, D., and T. Fourcaud. 2009. Crown structure and wood properties: Influence on tree sway and response to high winds. American Journal of Botany 96:885-896.

Simpson, P., and R. van Bossuyt. 1996. Tree-caused electric outages. Journal of Arboriculture 22:117-121.

Spatz, H-C., K. Bruchert, and J. Pfisterer. 2007. Multiple resonance damping or how do trees escape dangerously large oscillations? American Journal of Botany 94:1603-1611.

Sugden, M.J. 1962. Tree sway period - A possible new parameter for crown classification and stand competition. Forestry Chronicle 38:336-344.

Wilson, B.F. 2000. Apical control of branch growth and angle in woody plants. American Journal of Botany 87:601-607.

Zeng, B. 2003. Aboveground biomass partitioning and leaf development of Chinese subtropical trees following pruning. Forest Ecology and Management 173:135-144.

Jason W. Miesbauer (corresponding author)

The Morton Arboretum - Science and Conservation

Lisle, Illinois, U.S.

Edward F. Gilman

University of Florida - Environmental Horticulture

Gainesville, Florida 32606, U.S.

Mihai Giurcanu

University of Florida - Department of Statistics

Gainesville, Florida, U.S. 
Zusammenfassung. Die Kenntnis von dynamischen Baumeigenschaften ist wichtig, um die Fähigkeit zur Beurteilung von Baumrisiken zu verbessern. Es wurden über eine Periode von 2 Jahren an 16 Rotahornen (Acer rubrum L. 'Florida Flame') Zugversuche im Sommer und Winter ausgeführt und die natürliche Frequenz und das Entspannungsverhältnis zu kalkulieren. Ein Jahr vor der Testreihe wurden die Bäume eingeteilt in entweder hinauf laufende oder herab laufende Form und entsprechend geschnitten, um diese Form zu erhalten. Während der Sommertests wurden die Bäume geschnitten, um die bestimmte Form zu erhalten und die Tests wurden vor und nach dem Schnitt durchgeführt. Die Bäume wurden anschließend systematisch unterteilt, um die morphologischen und allometrischen Charakteristika zu messen. Nach oben offene Bäume hatten im Sommer und Winter eine höhere natürliche Frequenz als Bäume mit herab laufenden Kronen. Der Rückschnitt im Sommer ließ die Frequenz von offenkronigen Bäumen eher ansteigen als bei herab laufenden Kronenformen. Baumform und Rückschnitt hatten wenig Einfluss auf die Entspannung. Bäume mit herab laufenden Kronen hatten einen Großteil ihres Astwerks in der oberen Kronenhälfte im Gegensatz zu den offenkronigen Bäumen, was diese stärker dem durch Wind beeinflusstem Stress aussetzt und das Versagensrisiko erhöht.
Resumen. En el conocimiento de las propiedades dinámicas de los árboles es importante mejorar la capacidad para evaluar el riesgo. Se realizaron pruebas de tensión y liberación en 16 árboles de Acer rubrum L. 'Florida Flame' en el verano y el invierno en un período de dos años y se calculó la frecuencia natural y las relaciones de amortiguamiento. Un año antes de la prueba los árboles fueron designados como sea excurrentes o decurrentes y podados para imponer esa forma. Durante las pruebas de verano los árboles fueron podados para mantener la forma designada y las pruebas se llevaron a cabo antes y después de la poda. Los árboles fueron disectados sistemáticamente para medir las características morfológicas y alométricas. Los árboles excurrentes tenían una frecuencia natural más alta que los árboles decurrentes en verano como en invierno y la poda en verano aumentó la frecuencia de los árboles excurrentes más que árboles decurrentes. La forma de árbol y la poda tuvieron poco efecto en la relación de amortiguamiento. Los árboles decurrentes tuvieron un mayor porcentaje de su masa de ramas en la mitad superior de la corona que los árboles excurrentes, lo cual impone un estrés inducido por el viento más grande en sus troncos y aumenta el riesgo de fracaso. 